\title{
OCORRÊNCIA E ATIVIDADE DE FUNGOS MICORRÍZICOS ARBUSCULARES EM PLANTIOS DE EUCALIPTO (Eucalyptus sp.) NO LITORAL NORTE DA BAHIA, BRASIL ${ }^{1}$
}

\author{
Francisco de Sousa Lima², Ana Cristina Fermino Soares ${ }^{2}$ e Carla da Silva Sousa ${ }^{2}$
}

\begin{abstract}
RESUMO - Nas últimas décadas, tecnologias alternativas vêm sendo estudadas visando tornar o cultivo do eucalipto (Eucalyptus sp.) mais econômico e sustentável. Entre estas, as associações micorrízicas merecem destaque devido aos inúmeros benefícios que proporcionam às plantas hospedeiras. Este trabalho teve como objetivo avaliar a ocorrência e atividade de fungos micorrízicos arbusculares em plantios de eucalipto utilizados comercialmente pela Copener Florestal Ltda. no litoral norte da Bahia. Foi observada grande variabilidade na densidade de esporos (36,2 a 203,2 esporos em 50 g de solo), colonização micorrízica (10,6 a 57,8\%) e nos teores de glomalina facilmente extraível e total $\left(0,34\right.$ a $1,92 \mathrm{mg} \mathrm{g}$ de $\operatorname{solo}^{-1}$ e 0,48 a 3,88 mg g de $\mathrm{solo}^{-1}$ ) nos plantios de eucalipto. Os resultados neste estudo permitiram concluir que, embora os clones apresentem suscetibilidade à micorrização em condições de campo, variações nas características do solo afetam aspectos ecológicos dos fungos micorrízicos arbusculares nos plantios de eucalipto da Copener Florestal Ltda. no litoral norte da Bahia.
\end{abstract}

Palavras-chave: Espécies florestais, Micorrizas, Glomalina, Eucaliptus spp.

\section{OCCURRENCE AND ACTIVITY ARBUSCULAR MYCORRHIZAL FUNGI IN EUCALYPT (Eucalyptus sp.) PLANTATIONS IN THE NORTHERN COAST OF $B A H I A, B R A Z I L$}

\begin{abstract}
In recent decades, alternative technologies have been studied in order to make the cultivation of eucalyptus more economical and sustainable. Among these, the mycorrhizal associations deserve mention because of the many benefits they provide to host plants. Mycorrhizal fungi (AMF) form mutualistic association with plant roots, promoting greater uptake of nutrients to the host, which in turn yields products of photosynthesis to the fungus. With the establishment of the association, the plants become more resistant to adverse conditions such as nutrient-poor soil, low pH, high temperature, water stress, decreased microbial activity, among other biotic and abiotic stresses. This study aimed to evaluate the occurrence and activity of mycorrhizal fungi in eucalypt plantations used commercially by Copener Florestal Ltda. northern coast of Bahia. A high variability in the density of spores (36.2 to 203.2 spores in $50 \mathrm{~g}$ of soil), mycorrhizal colonization (10.6 to $57.8 \%$ ) and levels of easily extractable glomalin and total ( 0.34 to $1.92 \mathrm{mg} \mathrm{g-1} \mathrm{soil} \mathrm{and} 0.48$ to $\left.3.88 \mathrm{mg} \mathrm{g} \mathrm{soil}^{-1}\right)$ in plantations. The results of this study showed that although the clones showing susceptibility to mycorrhizal infection in field conditions, variations in soil characteristics affect the ecological aspects of mycorrhizal fungi in plantations of eucalyptus Copener Florestal Ltda. northern coast of Bahia.
\end{abstract}

Keywords: Forest species, Mycorrhizae, Glomalin. Eucaliptus spp.

\footnotetext{
${ }^{1}$ Recebido em 08.02.2011 aceito para publicação em 05.04.2013.

${ }^{2}$ Universidade Federal do Recôncavo da Bahia, UFRB, Brasil. E-mail:<fslsolos@yahoo.com $>,<$ ferminosoares@ gmail.com $>$ e<cssagro@yahoo.com.br>.
} 


\section{INTRODUÇÃO}

Como outros vegetais exóticos, a exemplo do café (Coffea arabica L.), da cana-de-açúcar (Saccharum officinarum L.) e da soja (Glycine max), o eucalipto encontrou no solo e no clima brasileiro condições ideais para produção em escala, de tal modo que praticamente todas as grandes indústrias de celulose e madeira do mundo estão presentes no Brasil (LOPES, 2008). Aliado à preservação das florestas nativas, os plantios de eucalipto sequestram 196 milhões de toneladas de carbono do ar, contribuindo para a sustentabilidade do planeta (QUEIROZ; BARRICHELO, 2007).

O eucalipto apresenta alta taxa de crescimento, plasticidade, variações nas propriedades da madeira e outros. Trata-se da espécie folhosa mais usada para obtenção de celulose, pela sua adaptabilidade a diferentes condições climáticas e regionais, bem como devido ao rápido crescimento até a idade de corte, comparativamente a outras espécies florestais produtoras de celulose (OLIVETTI NETO, 2009).

No Brasil, há 2,9 milhões de hectares de florestas plantadas predominantemente com Eucalyptus grandis que ocupam $55 \%$ da área total, seguidos de $17 \%$ com Eucalyptus saligna, 9\% com Eucalyptus urophylla, $2 \%$ com E. viminalis, $11 \%$ com híbridos de E. grandis x E. urophylla e $6 \%$ com outras espécies (CAMPOS et al., 2011). Minas Gerais é o maior produtor dessa cultura, respondendo por $29 \%$ do total cultivado, seguido por São Paulo (22\%) e Bahia (14\%) (ABRAF, 2009). Contudo, o êxito na formação de florestas de alta produção depende, em grande parte, da qualidade das mudas produzidas, que deverão sobreviver e resistir a condições adversas no campo após o transplantio, produzindo árvores com crescimento volumétrico economicamente desejável (GOMES et al., 1991). A produção de mudas de qualidade, sua sobrevivência e estabelecimento no campo são fatores primordiais para a obtenção do sucesso no plantio de espécies florestais em grande escala (SHIAVO et al., 2009).

Estudos sobre o efeito de fungos micorrízicos arbusculares (FMA) no crescimento e na sobrevivência de mudas de diversas espécies vegetais, principalmente florestais e fruteiras, são abordados na literatura (OLIVEIRA et al., 2003; SCHIAVO; MARTINS, 2003; SOARES; MARTINS, 2002; SONG et al., 2004; CAPRONI et al., 2005; LEAL et al., 2005), assim como estudos de ocorrência e diversidade de espécies de FMA em diversos ecossistemas naturais e agrícolas (BARNI; SINISCALCO, 2000; BENEDETTI et al., 2005).

As micorrizas arbusculares (MAs) são associações entre plantas e fungos do solo do filo Glomeromycota (SCHÜßLER et al., 2001). O benefício da associação para a planta surge do aumento da extensão da superfície de absorção e, em troca, o fungo é subsidiado por carboidratos fotoassimilados (HERRMAN et al., 2004). Além dos benefícios nutricionais para o hospedeiro, os FMA produzem no micélio externo uma glicoproteína denominada glomalina, que favorece a estabilidade de agregados no solo (WRIGHT; UPADHYAYA, 1998), sequestro de metais pesados (GONZÁLEZ-CHÁVEZ et al., 2004; CORNEJO et al., 2008); por ser rica em carbono e nitrogênio, apresenta-se como reservatório desses elementos no solo (RILLING et al., 2003; LOVERLOCK, 2004; NICHOLS; WRIGHT, 2006).

Trabalhos têm demonstrado que o estabelecimento da associação micorrízica em espécies de eucalipto e os benefícios da simbiose têm sido explorados comercialmente em diversas regiões do Brasil (COELHO et al., 1997; GOMES; TRUFEM, 1998; GRAZZIOTTI et al., 1998; ARAÚJO et al., 2004). Entretanto, poucas são as pesquisas sobre as associações micorrízicas com espécies florestais em condições de campo, e nesse caso são necessários estudos para se obter melhor compreeensão quanto aos benefícios que a simbiose micorrízica pode proporcionar à cultura do eucalipto. O conhecimento da condição micorrízica dos clones de eucalipto no campo e da eficiência simbiótica desses fungos servirá como suporte para otimizar o processo de produção de mudas de eucalipto micorrizadas, visando ao melhor desenvolvimento dos clones na fase de viveiro e melhor estabelecimento no campo.

Nesse sentido, o objetivo deste trabalho foi quantificar teores de glomalina, densidade de esporos e colonização micorrízica promovida por fungos micorrízicos arbusculares em plantios comerciais de eucalipto da Copener Florestal Ltda., no litoral norte da Bahia.

\section{MATERIAL E MÉTODOS}

\section{1. Área de estudo}

O estudo foi realizado em 20 áreas com plantios de eucalipto (Eucalyptus sp.) utilizados comercialmente pela Copener Florestal LTDA., que atua no litoral norte da Bahia ( $11^{\circ} 15^{\prime}$ 'S e $12^{\circ} 30^{\prime} \mathrm{S}, 37^{\circ} 30^{\prime} \mathrm{W}$ e $\left.38^{\circ} 45^{\prime} \mathrm{W}\right)$, com 
altitudes de 0 a 300 m. As áreas são localizadas nos Municípios de Alagoinhas, Inhambupe, Sátiro Dias, Entre Rios, Crisópolis e Itapicuru, todos no Estado da Bahia, ao Norte de Salvador.

Nessa região ocorrem quatro tipos bioclimáticos que se sucedem do litoral em direção ao interior: clima úmido, subúmido úmido, subúmido seco e semiárido. O tipo climático, segundo a classificação de Köppen, é As', ou seja, clima quente com estação seca no verão. As temperaturas médias anuais são de $25^{\circ} \mathrm{C}$, com pequenas oscilações mensais, com média das máximas de $29^{\circ} \mathrm{C}$ e média das mínimas de $20^{\circ} \mathrm{C}$. As chuvas concentram-se no período de abril a julho, com ocorrência de pequeno pico secundário em novembro/dezembro. As precipitações médias anuais variam de 700 a 2.000 $\mathrm{mm} / \mathrm{ano}$, do interior para o litoral.

Os povoamentos florestais encontram-se implantados sobre argissolos, latossolos e neossolos. Nos relevos ondulados, há predominância dos argissolos e nos relevos planos (tabuleiros) e suave ondulados ocorrem os latossolos e argissolos, associados ou não a neossolos. Os argissolos ocorrem nas rampas inferiores dos tabuleiros e áreas abaciadas com drenagem imperfeita. Próximo ao litoral ocorrem neossolos. Na Tabela 1, apresentam-se a descrição e caracterização das áreas nos plantios de eucalipto.

\subsection{Coleta das amostras de solo e raízes}

Foram coletadas de forma aleatória em caminho zigue-zague cinco amostras compostas formadas por 10 amostras simples em cada área, na profundidade de $0-15 \mathrm{~cm}$. As amostras de solo após as coletas foram secas ao ar, destorroadas, homogeneizadas, peneiradas em peneira de $2 \mathrm{~mm}$ e, em seguida, armazenadas a $4{ }^{\circ} \mathrm{C}$, em câmara fria, até a execução das análises. Realizaram-se caracterizações física, química e biológica (densidade de esporos e teor de glomalina) do solo, segundo a metodologia proposta pela Embrapa (1999), que é representada nas Tabelas 2 e 3 .

Foram escolhidas 10 árvores aleatoriamente dentro de cada área, onde amostras de raízes finas $(<2 \mathrm{~mm})$ foram coletadas na camada de $0-20 \mathrm{~cm}$ de profundidade e, em seguida, lavadas em água corrente e armazenadas em frascos de vidro contendo FAA (formaldeído $100 \%$ : etanol 70\% : ácido acético 100\% = 5:90:5) até a avaliação da colonização micorrízica.

Tabela 1 - Descrição e caracterização das áreas nos plantios de eucalipto localizados no litoral norte do Estado da Bahia, Brasil. Table 1 -Description and characterization of eucalyptus plantations in the areas located on the northern coast of Bahia, Brazil.

\begin{tabular}{|c|c|c|c|c|c|}
\hline Área & Projeto & Talhão & Solo* & Ano de plantio & Clone \\
\hline 1 & Cana verde & 18 & Ladx & 2004 & 0321 \\
\hline 2 & Laranjeiras & 13 & Ladx & 2005 & 1263 \\
\hline 3 & Salgado & 15 & Padx & 2005 & 1407 \\
\hline 4 & Nambis & 9 & RQo & 2007 & 1404 \\
\hline 5 & Porto seguro & 23 & RQo & 2008 & 1407 \\
\hline 6 & Encantado & 34 & Padx & 2004 & 0321 \\
\hline 7 & Sítio do meio & 22 & Padx & 2007 & 1404 \\
\hline 8 & Bebedouro & 23 & Padx & 2009 & 1407 \\
\hline 9 & Chile & 4 & RQo & 2005 & 2361 \\
\hline 10 & Patioba & 34 & RQo & 2006 & 1404 \\
\hline 11 & Rio torto & 7 & RQo & 2007 & 0321 \\
\hline 12 & Cham & 1 & Ladx & 2006 & 1404 \\
\hline 13 & Aporá & 7 & Ladx & 2008 & 6500 \\
\hline 14 & Pedra do sobrado & 3 & Padx & 2004 & 2361 \\
\hline 15 & Coração de leão & 50 & Padx & 2007 & 1404 \\
\hline 16 & Caravelle & 6 & Padx & 2009 & 6500 \\
\hline 17 & Crumay & 16 & RQo & 2004 & 0670 \\
\hline 18 & Coração de leão & 28 & RQo & 2006 & 0321 \\
\hline 19 & Rio branco & 5 & RQo & 2009 & 1407 \\
\hline 20 & Rio negro & 2 & Ladx & 2005 & 1404 \\
\hline
\end{tabular}

* Solo: Ladx = Latossolo amarelo distrocoeso; Padx = Argissolo amarelo distrocoeso; RQo = Neossolo quartzarênico órtico. 
Tabela 2 - Caracterização química do solo nos plantios de eucalipto localizados no litoral norte do Estado da Bahia, Brasil. Table 2 -Chemical characterization of soil in the eucalyptus plantations located on the northern coast of Bahia, Brazil.

\begin{tabular}{|c|c|c|c|c|c|c|c|c|c|c|c|c|}
\hline \multirow{2}{*}{ Área } & $\mathrm{pH}$ & $\mathrm{P}$ & K & $\mathrm{Ca}$ & $\mathrm{Mg}$ & $\mathrm{Ca}+\mathrm{Mg}$ & $\mathrm{Al}$ & $\mathrm{Na}$ & SB & CTC & \multirow{2}{*}{$\begin{array}{l}\mathrm{V} \\
\%\end{array}$} & \multirow{2}{*}{$\frac{\text { M.O. }}{\mathrm{g} / \mathrm{kg}}$} \\
\hline & \multicolumn{3}{|c|}{$\left(\mathrm{H}_{2} \mathrm{O}\right)\left(\mathrm{mg} / \mathrm{dm}^{3}\right)$} & \multicolumn{7}{|c|}{$\mathrm{cmolc} / \mathrm{dm}^{3}$} & & \\
\hline 1 & 5,6 & 34 & 0,17 & 2,70 & 1,30 & 4,00 & 0,0 & 0,05 & 4,22 & 7,63 & 55 & 19,97 \\
\hline 2 & 5,4 & 30 & 0,06 & 1,00 & 0,50 & 1,50 & 0,1 & 0,03 & 1,59 & 4,01 & 40 & 6,93 \\
\hline 3 & 6,1 & 139 & 0,33 & 3,00 & 1,20 & 4,20 & 0,0 & 0,06 & 4,59 & 6,57 & 70 & 10,86 \\
\hline 4 & 6,9 & 7 & 0,06 & 3,00 & 0,30 & 3,30 & 0,0 & 0,03 & 3,39 & 3,94 & 86 & 8,59 \\
\hline 5 & 5,6 & 7 & 0,05 & 0,70 & 0,20 & 0,90 & 0,1 & 0,01 & 0,97 & 3,17 & 31 & 6,31 \\
\hline 6 & 5,8 & 5 & 0,03 & 1,60 & 0,40 & 2,00 & 0,0 & 0,03 & 2,05 & 3,81 & 54 & 8,07 \\
\hline 7 & 5,3 & 85 & 0,27 & 1,70 & 0,60 & 2,30 & 0,1 & 0,04 & 2,61 & 5,69 & 46 & 16,56 \\
\hline 8 & 5,3 & 85 & 0,27 & 1,70 & 0,60 & 2,30 & 0,1 & 0,04 & 2,61 & 5,69 & 46 & 16,56 \\
\hline 9 & 5,0 & 60 & 0,02 & 0,30 & 0,20 & 0,50 & 0,3 & 0,02 & 0,54 & 2,52 & 21 & 5,07 \\
\hline 10 & 5,3 & 167 & 0,06 & 1,10 & 0,30 & 1,40 & 0,1 & 0,03 & 1,49 & 3,69 & 40 & 7,55 \\
\hline 11 & 5,3 & 167 & 0,16 & 0,20 & 0,20 & 0,40 & 0,2 & 0,04 & 0,61 & 2,48 & 25 & 6,42 \\
\hline 12 & 4,9 & 166 & 0,03 & 0,30 & 0,30 & 0,60 & 0,5 & 0,03 & 0,66 & 1,98 & 33 & 10,14 \\
\hline 13 & 5,2 & 161 & 0,90 & 2,60 & 0,90 & 3,50 & 0,0 & 0,16 & 4,56 & 7,64 & 60 & 15,94 \\
\hline 14 & 5,2 & 158 & 0,04 & 0,60 & 0,30 & 0,90 & 0,2 & 0,05 & 1,00 & 5,95 & 17 & 16,56 \\
\hline 15 & 5,4 & 157 & 0,28 & 0,90 & 0,30 & 1,20 & 0,3 & 0,07 & 1,56 & 5,30 & 29 & 12,11 \\
\hline 16 & 5,6 & 21 & 0,18 & 3,00 & 0,60 & 3,60 & 0,0 & 0,04 & 3,82 & 7,01 & 54 & 16,87 \\
\hline 17 & 5,3 & 41 & 0,02 & 0,80 & 0,30 & 1,10 & 0,3 & 0,03 & 1,15 & 3,68 & 31 & 11,18 \\
\hline 18 & 5,1 & 7 & 0,02 & 0,40 & 0,20 & 0,60 & 0,5 & 0,03 & 0,65 & 3,07 & 21 & 7,97 \\
\hline 19 & 5,4 & 10 & 0,05 & 0,80 & 0,30 & 1,10 & 0,2 & 0,02 & 1,18 & 3,82 & 31 & 9,83 \\
\hline 20 & 7,2 & 24 & 0,19 & 6,50 & 1,20 & 7,70 & 0,0 & 0,08 & 7,98 & 7,98 & 100 & 31,25 \\
\hline
\end{tabular}

\subsection{Densidade de esporos de fungos micorrízicos arbusculares (FMA)}

Os esporos de FMA foram extraídos de $50 \mathrm{~g}$ das amostras de solo através da técnica do peneiramento úmido (GERDEMAM; NICOLSON, 1963), seguido por centrifugação em água e solução de sacarose $50 \%$ (JENKINS, 1964). Nesse procedimento, cada amostra de solo foi transferida para um recipiente contendo $1.000 \mathrm{~mL}$ de água e homogeneizados à mão, para desestruturação de todos os torrões (aglomerados). Na sequência, o material foi decantado por $1 \mathrm{~min}$, sendo o sobrenadante vertido sobre três peneiras sobrepostas de $50 \mu \mathrm{m}, 100 \mu \mathrm{m}$ e $250 \mu \mathrm{m}$. $\mathrm{O}$ material retido nas peneiras foi recolhido em um tubo de ensaio e submetido à centrifugação em água (3.000 rpm) por $3 \mathrm{~min}$. O sobrenadante foi descartado e ao material depositado no fundo, adicionada solução de sacarose $70 \%$. O material foi ressuspenso com o auxílio de bastão de vidro e os tubos de ensaio, novamente levados à centrífuga $(2.000 \mathrm{rpm})$ por $1 \mathrm{~min}$. O sobrenadante foi vertido na peneira de $50 \mu \mathrm{m}$ e os esporos nela retidos, lavados em água corrente para a retirada do excesso de sacarose e transferidos para placa canaletada, em que foi realizada a contagem com o auxílio de microscópio estereoscópico (40x).

\subsection{Teores de glomalina facilmente extraível e glomalina total}

Foi determinado o teor de glomalina facilmente extraível (GFE) nas amostras de solo, através do método proposto por Wright e Upadhyaya (1998). Para extração da GFE, 0,25 g de solo foi pesado e transferido para tubos de ensaio, sendo adicionados $2 \mathrm{~mL}$ de citrato de sódio (20 mM; pH 7,0). Os tubos foram devidamente identificados, vedados com papel-alumínio e parafilme e, em seguida, autoclavados por $30 \mathrm{~min}$ a $121^{\circ} \mathrm{C}$. Após a autoclavagem, o sobrenadante foi retirado e transferido para tubos de Eppendorf, centrifugado (10.000 rpm) por 5 min e, em seguida, armazenado em frascos de penicilina a $4^{\circ} \mathrm{C}$ até a quantificação. A extração da glomalina total (GT) foi realizada através da adição de $2 \mathrm{~mL}$ de citrato de sódio ( $50 \mathrm{mM}$; pH 8,0) ao sedimento resultante da extração da GFE, seguido de autoclavagem $\left(121^{\circ} \mathrm{C} / 1 \mathrm{~h}\right)$, por repetidas vezes, até o sobrenadante não apresentar coloração marrom-avermelhada, característica da glomalina. Os sobrenadantes resultantes dos ciclos de extração da GT foram centrifugados (10.000 rpm/5 min) e armazenados em um único frasco de penicilina. Conforme o método de Bradford (1976), uma 
Tabela 3 - Densidade de esporos (D.E.), colonização micorrízica (C.M.), teor de glomalina facilmente extraível (GFE), total (GT), carbono da glomalina (C-G) e relação carbono da glomalina/carbono do solo (relação C-G/C-S) nos plantios de eucalipto localizados no litoral norte do Estado da Bahia, Brasil.

Table 3 - Spore density (SD), mycorrhizal colonization (MC), content easily extractable glomalin (EEG), total (GT), glomalin carbon (GC) and ratio of glomalin carbon / carbon in the soil (the ratio CG / CS) in plantations eucalyptus located on the northern coast of Bahia, Brazil.

\begin{tabular}{|c|c|c|c|c|c|c|}
\hline \multirow{2}{*}{ Área } & \multirow{2}{*}{$\begin{array}{c}\text { D.E. } \\
\left(50 \mathrm{~g}^{-1} \text { de solo }\right)\end{array}$} & \multirow{2}{*}{$\begin{array}{l}\text { C.M. } \\
(\%)\end{array}$} & G.F.E. & G.T & C-G & \multirow{2}{*}{$\begin{array}{c}\text { C-G/C-S } \\
(\%)\end{array}$} \\
\hline & & & \multicolumn{3}{|c|}{$\left(\mathrm{mg} \mathrm{g}^{-1}\right.$ solo $)$} & \\
\hline 1 & $78,7 \mathrm{c}$ & $57,8 \mathrm{a}$ & $0,87 \mathrm{~d}$ & $1,58 \mathrm{c}$ & $0,68 \mathrm{c}$ & $5,87 \mathrm{~d}$ \\
\hline 2 & $81,2 \mathrm{c}$ & $31,3 \mathrm{c}$ & $1,05 \mathrm{c}$ & $1,37 \mathrm{c}$ & $0,59 \mathrm{c}$ & $14,62 \mathrm{c}$ \\
\hline 3 & $70,0 \mathrm{~d}$ & $42,5 b$ & $0,50 \mathrm{e}$ & $0,92 d$ & $0,40 \mathrm{~d}$ & $6,30 \mathrm{~d}$ \\
\hline 4 & $89,7 \mathrm{c}$ & $41,7 b$ & $0,34 \mathrm{f}$ & $0,48 \mathrm{~d}$ & $0,21 \mathrm{~d}$ & $4,16 \mathrm{~d}$ \\
\hline 5 & $126,7 b$ & $32,5 \mathrm{c}$ & $0,63 \mathrm{e}$ & $0,67 d$ & $0,29 d$ & $7,88 \mathrm{~d}$ \\
\hline 6 & $100,2 \mathrm{c}$ & $31,1 \mathrm{c}$ & $1,40 \mathrm{~b}$ & $1,40 \mathrm{c}$ & $0,60 c$ & $12,83 \mathrm{c}$ \\
\hline 7 & $36,2 \mathrm{e}$ & $34,4 \mathrm{c}$ & $1,92 \mathrm{a}$ & $2,45 b$ & $1,06 \mathrm{~b}$ & $11,00 \mathrm{c}$ \\
\hline 8 & $129,0 \mathrm{~b}$ & $29,9 c$ & $0,80 \mathrm{~d}$ & $3,49 \mathrm{a}$ & $1,51 \mathrm{a}$ & $29,92 \mathrm{a}$ \\
\hline 9 & $32,5 \mathrm{e}$ & $29,4 c$ & $1,29 b$ & $2,04 \mathrm{c}$ & $0,88 \mathrm{c}$ & $15,64 \mathrm{c}$ \\
\hline 10 & $71,5 \mathrm{~d}$ & $29,7 \mathrm{c}$ & $0,60 \mathrm{e}$ & $1,55 \mathrm{c}$ & $0,67 \mathrm{c}$ & $15,19 \mathrm{c}$ \\
\hline 11 & $94,0 \mathrm{c}$ & $33,0 \mathrm{c}$ & $0,88 \mathrm{~d}$ & $1,63 \mathrm{c}$ & $0,70 \mathrm{c}$ & $18,83 \mathrm{~b}$ \\
\hline 12 & $55,0 \mathrm{~d}$ & $32,3 \mathrm{c}$ & $0,90 \mathrm{~d}$ & $3,88 \mathrm{a}$ & $1,67 \mathrm{a}$ & $28,37^{\mathrm{a}}$ \\
\hline 13 & $92,7 \mathrm{c}$ & $10,6 \mathrm{~d}$ & $0,96 \mathrm{~d}$ & $1,63 \mathrm{c}$ & $0,70 \mathrm{c}$ & $7,58 \mathrm{~d}$ \\
\hline 14 & $76,5 \mathrm{c}$ & $40,3 b$ & $1,20 b$ & $3,34 \mathrm{a}$ & $1,44 \mathrm{a}$ & $14,98 \mathrm{c}$ \\
\hline 15 & $37,5 \mathrm{e}$ & $39,1 \mathrm{~b}$ & $0,77 \mathrm{~d}$ & $0,93 \mathrm{~d}$ & $0,40 \mathrm{~d}$ & $5,67 \mathrm{~d}$ \\
\hline 16 & $48,7 \mathrm{~d}$ & $36,0 \mathrm{c}$ & $1,03 \mathrm{c}$ & $1,55 \mathrm{c}$ & $0,67 \mathrm{c}$ & $6,81 \mathrm{~d}$ \\
\hline 17 & $203,2 \mathrm{a}$ & $31,5 \mathrm{c}$ & $1,05 \mathrm{c}$ & $1,28 \mathrm{c}$ & $0,55 \mathrm{c}$ & $8,50 \mathrm{~d}$ \\
\hline 18 & $110,0 \mathrm{~b}$ & $39,9 b$ & $0,67 \mathrm{e}$ & $0,71 \mathrm{~d}$ & $0,31 \mathrm{~d}$ & $6,65 \mathrm{~d}$ \\
\hline 19 & $51,7 \mathrm{~d}$ & $32,7 \mathrm{c}$ & $0,54 \mathrm{e}$ & $1,36 \mathrm{c}$ & $0,59 \mathrm{c}$ & $10,31 \mathrm{~d}$ \\
\hline 20 & $88,5 \mathrm{c}$ & $33,1 \mathrm{c}$ & $1,10 \mathrm{c}$ & $3,00 \mathrm{~b}$ & $1,29 b$ & $7,11 \mathrm{~d}$ \\
\hline $\mathrm{CV}(\%)$ & 8,73 & 10,83 & 13,75 & 28,37 & 28,43 & 26,38 \\
\hline
\end{tabular}

Médias seguidas pela mesma letra na coluna não diferem estatisticamente entre si pelo teste de Scott \& Knott a $5 \%$ de probabilidade. Means followed by the same letter in column do not differ significantly by the Scott \& Knott test at $5 \%$ probability.

alíquota de $50 \mu \mathrm{L}$ do sobrenadante obtido, juntamente com 2,5 mL do reagente azul de comassié blue G-250, foi utilizada para quantificação dos teores de GFE e GT (mg/g de solo ${ }^{-1}$ ), tendo como curva-padrão soro albumina bovina (BSA). O carbono da glomalina (C-G) foi estimado a partir da glomalina total, considerando-se que o carbono representa $43,1 \%$ da molécula (RILLING et al., 2003) e expresso em mg g${ }^{1}$ solo. O percentual de contribuição da glomalina para o carbono total do solo foi calculado com base na relação carbono da glomalina (C-G)/carbono total do solo (C-S).

\subsection{Colonização micorrízica}

As raízes finas de eucalipto coletadas nas áreas $(<2 \mathrm{~mm})$ foram lavadas repetidas vezes em água destilada e, em seguida, imersas em solução de $\mathrm{KOH} 10 \%$ por $24 \mathrm{~h}$, em temperatura ambiente, para serem diafanizadas. Após esse período, foram lavadas com água destilada, tratadas com $\mathrm{H}_{2} \mathrm{O}_{2}$ alcalina por 45 min e, em seguida, com $\mathrm{HCl} 1 \%$, por $3 \mathrm{~min}$. Posteriormente, foram imersas em solução de azul de trypan $0,05 \%$ de lactoglicerol por $24 \mathrm{~h}$, em temperatura ambiente (KOSKE; GEMMA, 1989), e, após esse período, conservadas em lactoglicerol ácido até a avaliação. A avaliação da porcentagem de colonização micorrízica foi realizada através do método da placa quadriculada (GIOVANNETTI; MOSSE, 1980). Nesse método, fragmentos de raízes coradas foram colocados em placa quadriculada (quadrículas de $1,27 \mathrm{~cm}$ ) e observados em microscópio estereoscópico (40x), sendo contados 100 segmentos de raiz, que fizerem interseção com as linhas verticais e horizontais, registrando-se o número de segmentos colonizados. Foram considerados positivos os segmentos de raízes que apresentavam estruturas típicas de fungos micorrízicos, como vesículas, arbúsculos, hifas e pelotões. 


\subsection{Análise dos dados}

Os dados foram submetidos à analise de variância e teste de Scott \& Knott a 5\% de probabilidade, para a comparação das médias, utilizando o programa estatístico SISVAR. Os dados referentes à densidade de esporos e colonização micorrízica foram transformados, respectivamente, por $(\mathrm{x}+0,5)^{1 / 2} \mathrm{e}$ arcosseno $\sqrt{x / 100}$. Foram realizadas análises de correlação simples de Pearson (r) entre a densidade de esporos, colonização micorrízica, teor de glomalina facilmente extraível e total e as características químicas do solo: teores de fósforo, matéria orgânica e $\mathrm{pH}$, utilizando o programa estatístico SAS.

\section{RESULTADOS}

De modo geral, foram encontrados valores médios referentes à densidade de esporos variando entre 32,5 e 203,2 esporos em $50 \mathrm{~g}$ de solo, nas áreas 9 e 17, respectivamente (Tabela 3 ). A segunda maior densidade de esporos de FMA foi observada na área 8 (129 esporos em 50 g de solo), seguida das áreas 5 e 18 (126,7 e 110 esporos em $50 \mathrm{~g}$ de solo, respectivamente).

Os resultados de colonização micorrízica apontaram porcentagens variando de 10,6 a 57,8\% (áreas 13 e 1, respectivamente). As médias de colonização nas áreas $3,4,14,15$ e 18 não diferiram significativamente, ocorrendo o mesmo com as áreas 2, 5, 6, 7, 8, 9, 10, 11, 12, 16, 17, 19 e 20. Entre as 20 áreas de eucalipto estudadas, apenas a área 1 apresentou alto grau de colonização (57,8\%), enquanto as demais áreas, grau de colonização médio (29,4 a 42,5\%), segundo a escala proposta por Carneiro et al. (1998). Apenas a área 13 teve valor correspondente à baixa colonização micorrízica $(10,6 \%)$.

Os valores de densidade de esporos e colonização micorrízica não apresentaram correlação significativa com o pH e os teores de $\mathrm{K}, \mathrm{Ca}, \mathrm{Mg}$, Al e matéria orgânica do solo. Para o teor de P nos solos, os coeficientes de correlação com a densidade de esporos e colonização micorrízica foram de $\mathrm{r}=-0,24(\mathrm{p}<0,05)$ e $\mathrm{r}=-0,22(\mathrm{p}$ $<0,05)$, respectivamente. Não houve correlação significativa entre a densidade de esporos e a idade dos plantios. A colonização micorrízica correlacionou-se positivamente com a idade dos plantios $(r=0,29 ; p<0,01)$

Maiores teores de GFE foram registrados na área 7 (1,92 $\mathrm{mg} \mathrm{g} \mathrm{de} \mathrm{solo-1}^{-1}$, seguido das áreas 6, 9 e 14 (1,40,1,29 e 1,20 mg g de solo, respectivamente), que não diferiram estatisticamente entre si. As áreas 4, 3, $5,10,18$ e 19 apresentaram menores teores de GFE, sendo observados valores entre 0,34 e $0,67 \mathrm{mg}$ g de solo $^{-1}$. Observou-se correlação positiva entre o teor de GFE e a concentração de matéria orgânica do solo $(\mathrm{r}=0,25 ; \mathrm{p}>0,05)$. Para o $\mathrm{pH}$, o coeficiente de correlação com o teor de GFE foi negativo $(r=-0,21 ; p>0,05)$. Não houve correlação significativa entre o teor de GFE e os teores de P, K, Ca, Mg e Al no solo. Houve correlação entre o teor de GFE e a idade dos plantios, cujo coeficiente de correlação foi $r=0,27(p>0,05)$.

As áreas 8, 12 e 14 apresentaram maiores teores de glomalina total (GT), sendo observados valores que variaram de 3,34 a $3,88 \mathrm{mg}$ g de solo ${ }^{-1}$, representando até $29,92 \%$ do C total do solo. Menores teores de GT foram quantificados nas áreas 3, 4, 5 e 15 (0,48 a 0,93 $\mathrm{mg}$ g de solo $^{-1}$ ).

\section{DISCUSSÃO}

A densidade de esporos de FMA entre as áreas estudadas apresentou valores entre 32,5 e 203,5 esporos por $50 \mathrm{~g}$ de solo, correspondendo a uma variação de até $625,2 \%$. Em um estudo realizado em plantios de eucalipto localizados na região Leste de Minas Gerais, Campos et al. (2011) observaram valores entre $61 \mathrm{e}$ 1106 esporos em $100 \mathrm{~g}$ de solo (variação de 1893,3\%). Araújo et al. (2004) também verificaram grande variação na densidade de esporos $(3.666,7 \%)$ em um estudo realizado anteriormente nesses plantios. Segundo Brundrett et al. (1996), a densidade de esporos de FMA na rizosfera geralmente é bastante variável e está relacionada com a distribuição, morfologia e idade fisiológica das raízes, assim como depende de outros fatores que influenciam na esporulação, como pluviometria, temperatura, período de insolação e espécies de FMA.

Assim como a densidade de esporos, a colonização micorrízica também apresentou grande variação (445,3\%). Estudos têm demonstrado que a colonização micorrízica em eucalipto é bastante variável. Araújo et al. (2004) encontraram valores médios de colonização de 10 a $96,6 \%$, enquanto Santos (2001) obteve valores médios entre $27,8 \%$ e $58,3 \%$ nas épocas úmida e seca, respectivamente. Adjoud et al. (1996), avaliando o efeito da inoculação de 11 espécies de eucalipto com FMA, verificaram que o grau de colonização micorrízica variou de $1 \%$ (E. dumosa/G. mosseae) a $80 \%$ (E. urophylla/ G. intraradices). 
A ausência de correlação significativa entre a densidade de esporos e a colonização micorrízica com o pH e os teores de $\mathrm{K}, \mathrm{Ca}, \mathrm{Mg}$, Al e matéria orgânica do solo sugere que essas variáveis não influenciaram no estabelecimento da associação micorrízica. Contudo, valores de $\mathrm{P}$ nos solos apresentaram correlação negativa com a densidade de esporos e colonização micorrízica. Segundo Moreira e Siqueira (2006), geralmente, em concentrações de fósforo próximas do ótimo para o crescimento da planta hospedeira, já ocorre inibição da colonização micorrízica, porque afeta os sinais moleculares que desencadeiam a associação, que são emitidos pela planta hospedeira. Houve correlação positiva entre a colonização micorrízica e a idade dos plantios. A colonização micorrízica é uma característica que pode ser afetada por inúmeros fatores, como a espécie vegetal, a idade da planta, a densidade de raízes, dos propágulos fúngicos no solo e do tipo de manejo empregado no solo na hora do plantio, entre outros (CAMPOS et al., 2011).

Os teores de glomalina facilmente extraível (GFE) nas áreas estudadas variaram de 0,34 a 1,92 mg g de solo $^{-1}$, o que corresponde a uma diferença de 464,7\%. Embora os mecanismos que regulam a produção de glomalina ainda não estejam bem compreendidos (PURIN; RILLIG, 2007), acredita-se que características do solo, condições climáticas, presença e tipo de vegetação, espécie fúngica, entre outros fatores, podem influenciar a concentração de glomalina presente nos solos (WRIGHT et al., 1996; RILLIG et al., 2001; RIGHT; ANDERSON, 2002). Neste estudo, foi possível verificar grande variabilidade nas características químicas dos solos entre os plantios de eucalipto (Tabela 1), o que pode ter influenciado nos teores de glomalina registrados. Além disso, como demonstrado no estudo de correlação (Tabela 4), houve influência da idade dos plantios sobre o teor de glomalina, ou seja, conforme avanço da idade dos plantios e maior o teor de glomalina presente nos solos.

O teor de GFE correlacionou-se positivamente com os teores de matéria orgânica nos solos. Correlação positiva entre as frações de glomalina e o teor de matéria orgânica tem sido registrada em solos naturais e cultivados (WRIGHT et al., 1996; BIRD et al., 2002; RILLING et al., 2003; NICHOLS; WRIGHT, 2005). Segundo alguns autores, a glomalina favorece a formação de agregados no solo que protegem materiais orgânicos da
Tabela 4 - Coeficiente de correlação linear simples entre densidade de esporos (DE), colonização radicular (CR) e teor de glomalina facilmente extraível (GFE) e os teores de nutrientes nos solos coletados nos plantios de eucalipto no litoral norte da Bahia.

Table 4 -Simple linear correlation coefficient between spore density (SD), mycorrhizal colonization (MC), content easily extractable glomalin (EEG) and the nutrient content in soils in plantations eucalyptus located on the northern coast of Bahia, Brazil.

\begin{tabular}{|c|c|}
\hline Interação & Valor $r$ \\
\hline $\mathrm{DE} \times \mathrm{pH}$ & $\mathrm{ns}$ \\
\hline $\mathrm{DE} \times \mathrm{P}$ & $-0,24 *$ \\
\hline DE $\times \mathrm{K}$ & $\mathrm{ns}$ \\
\hline $\mathrm{DE} \times \mathrm{Ca}$ & $\mathrm{ns}$ \\
\hline DE $\times$ Mg & $\mathrm{ns}$ \\
\hline DE x Al & $\mathrm{ns}$ \\
\hline DE $\times \operatorname{MOS}^{1}$ & $\mathrm{~ns}$ \\
\hline $\mathrm{DE} \times \mathrm{ID}^{2}$ & $\mathrm{~ns}$ \\
\hline $\mathrm{CR} \times \mathrm{pH}$ & $\mathrm{ns}$ \\
\hline $\mathrm{CR} \times \mathrm{P}$ & $-0,22 *$ \\
\hline $\mathrm{CR} \times \mathrm{K}$ & $\mathrm{ns}$ \\
\hline $\mathrm{CR} \times \mathrm{Ca}$ & $\mathrm{ns}$ \\
\hline $\mathrm{CR} \times \mathrm{Mg}$ & $\mathrm{ns}$ \\
\hline CR x Al & $\mathrm{ns}$ \\
\hline CR $\times$ MOS & $\mathrm{ns}$ \\
\hline CR x ID & $0,29 * *$ \\
\hline GFE $\times \mathrm{pH}$ & $-0,21 *$ \\
\hline GFE $\times$ P & $\mathrm{ns}$ \\
\hline GFE x K & $\mathrm{ns}$ \\
\hline GFE x Ca & $\mathrm{ns}$ \\
\hline GFE x Mg & $\mathrm{ns}$ \\
\hline GFE $\times$ MOS & $0,25 *$ \\
\hline GFE x Al & $\mathrm{ns}$ \\
\hline GFE $x$ ID & $0,27 *$ \\
\hline
\end{tabular}

NS: não-significativo; $* * *, * * *$ significativos a 5,1 e $0,1 \%$, respectivamente.

${ }^{1} \mathrm{ID}=$ Idade dos plantios

decomposição microbiana (WRIGHT; UPADHYAYA, 1998; RILLING, 2004). Para Treseder e Turner (2007), decompositores preferem outros materiais orgânicos em vez da glomalina quando o C orgânico é predominante. Contudo, Bedini et al. (2007) acreditavam que a glomalina e o C orgânico apresentam semelhante dinâmica de decomposição.

Foi observada correlação negativa entre o pH do solo e o teor de GFE. Alguns autores também observaram correlação negativa entre teores de glomalina e pH do solo (RILLING et al., 2003; HADDAD; SARKAR, 2003). Possivelmente na condição de $\mathrm{pH}$ ácido, há maior preservação da glomalina, uma vez que essa condição

Revista Árvore, Viçosa-MG, v.37, n.2, p.245-255, 2013 
não é favorável para a presença e atividade de microrganismos decompositores dessa molécula, como as actinobactérias.

Foi observada variação de até $708,3 \%$ no teor de glomalina total (GT) entre as áreas de plantio de eucalipto. Houve correlação positiva entre o teor de GT e o teor de matéria orgânica nos solos. De acordo com Jone e Jakosen (1995), o desenvolvimento das hifas dos FMA pode aumentar em resposta à alta concentração da matéria orgânica, o que resulta em aumento nos teores de glomalina nos solos, uma vez que, quando as hifas de FMA morrem e se decompõem, a glomalina é liberada para o solo (TRESEDER; ALLEN, 2000).

Observou-se que algumas áreas (8 e 12) apresentaram baixo teor de GFE, entretanto foram registrados os maiores valores de GT (Tabela 3). Apesar de as frações de glomalina terem a mesma origem, ou seja, produzidas por FMA, elas compreendem reservatórios com diferentes taxas de estabilidade e reposição (PREGER et al., 2007). A GFE representa a fração recentemente depositada que ainda não sofreu transformações bioquímicas no solo (WRIGHT et al., 1996), portanto mais suscetível à decomposição microbiana. A GT apresenta-se fortemente ligada às argilas, correspondendo ao reservatório total dessa proteína depositada ao longo do tempo no solo, seja pela secreção hifálica, seja pela decomposição de esporos e hifas (DRIVER et al., 2005).

O estudo de fungos micorrízicos em áreas de plantio com eucalipto é importante para seleção de espécies fúngicas nativas que poderão ser úteis no estudo das relações ecológicas entre o fungo simbionte e a planta hospedeira. Os resultados deste estudo permitiram concluir que, embora os clones apresentem suscetibilidade à micorrização em condições de campo, variações nas características do solo afetam aspectos ecológicos dos fungos micorrízicos arbusculares nos plantios de eucalipto da Copener Florestal Ltda. no litoral norte da Bahia. Futuros estudos são necessários para melhor compreensão dos aspectos ecológicos dos FMA e seus benefícios à cultura do eucalipto.

\section{AGRADECIMENTOS}

Ao CNPq, pela concessão de bolsa de PósDoutorado Júnior ao primeiro autor; e ao Sr. Jacyr Mesquita Alves da Copener Florestal Ltda., pelo apoio, disponibilizando a estrutura da empresa para a realização desta pesquisa.

Revista Árvore, Viçosa-MG, v.37, n.2, p.245-255, 2013

\section{REFERÊNCIAS}

ABRAF. Anuário Estatístico da Associação Brasileira de Florestas Plantadas 2009 - Ano Base 2008. Brasília, 81 p. Disponível em: <http:// www.abraflor.org.br/estatisticas/anuario-ABRAF2008.pdf>. Acesso em 20 set. 2009.

ARAÚJO, C. V. M. et al. Micorriza arbuscular em plantações de Eucalyptus cloeziana F. Muell no litoral norte da Bahia, Brasil. Acta Botânica Brasílica, v.18, n.3, p.513-520, 2004

BARNI, E.; SINISCALCO, C. Vegetation dynamics and arbuscular mycorrhiza in old-fields successions od the western Italian Alps. Micorrhiza, v.10, n.1, p.63-72, 2000.

BEDINI, S. et al. Effects of long-term land use on arbuscular mycorrhizal fungi and glomalin-related soil protein. Agriculture, Ecosystems and Environment, v.120, p.463-466, 2007.

BENEDETTI, T. et al. Diversidade de fungos micorrízicos arbusculares na cultura do milho após uso de espécies de plantas de cobertura de solo. Revista de Ciências

Agroveterinárias, v.4, n.1, p.44-51, 2005.

BIRD, S. B. et al. Spatial heterogeneity of aggregate stability and soil carbon in semi-arid rangeland. Environmental Pollution, v. 116, n.3, p.445-455, 2002

BRADFORD, M. M. A rapid and sensitive method for the quantification of micrograms quantites of protein utilizing the principle of protein-dye binding. Analyses Biochemists, v.72, p.248-254, 1976.

BRUNDRETT, M. C.; ASHWATH, N.; JASPER, D. A. Mycorrhizas in the Kakadu region of tropical Australia. Plant and Soil, v.184, n.1, p.173-184, 1996.

CAMPOS, D. T. S. et al. Colonização micorrízica em plantios de eucalipto. Revista Árvore, v.35, n.5, p.965-974, 2011.

CAPRONI, A. L. et al. Fungos micorrízicos arbusculares em estéril revegetado com Acacia mangium, após mineração com bauxita. Revista Árvore, v.29, n.3, p.373-381, 2005. 
CARNEIRO, M. A. C. et al. Micorriza arbuscular em espécies arbóreas e arbustivas nativas de ocorrência no sudeste do Brasil. Cerne, v.4, n.1, p.129-145, 1998.

COELHO, F. B. et al. Caracterização e incidência de fungos micorrízicos em povoamentos de Eucalyptus grandis e Eucalyptus saligna, nos municípios de Botucatu, São José dos Campos e São Miguel Arcanjo, São Paulo. Revista Árvore, v.21, n.4, p.563-573, 1997.

CORNEJO, P. et al. Glomalin-related soil protein in a Mediterranean ecosystem affected by a copper smelter and its contribuition to $\mathrm{Cu}$ and $\mathrm{Zn}$ sequestration. Science of the Total Environment, v.406, n.1-2, p.154-160, 2008.

DRIVER, J. D.; HOLBEN, W. E.; RILLING, M. C. Characterization of glomalin as a hyphal wall component of arbuscular mycorrhizal fungi. Soil Biology \& Biochemistry, v.37, n.1, p.101-106, 2005.

\section{EMPRESA BRASILEIRA DE PESQUISA} AGROPECUÁRIA - EMBRAPA. Manual de análises químicas de solos, plantas e fertilizantes. Brasília: Embrapa Comunicação para Transferência de Tecnologia de Tecnologia, $1999.370 \mathrm{p}$.

GERDEMANN, J. W.; NICOLSON, T. H. Spores of mycorrhizal Endogone species extracted from soil by wet sieving and decanting. Translation British Mycology Society, v.46, n.2, p.235244, 1963.

GIOVANNETTI, M.; MOSSE, B. An evaluation of techniques to measure vesicular-arbuscular mycorrhizal infection in roots. New

Phytologist, v.84, n.3, p.484-500, 1980.

GOMES, S. P.; TRUFEM, S. F. B. Fungos micorrízicos arbusculares (Glomales, Zygomycota) na Ilha dos Eucaliptos, Represa do Guarapiranga, São Paulo, SP. Acta Botanica Brasílica, v.12, n.3, p.393-401, 1998.

GONZÁLEZ-CHAVÉZ, M. C. et al. The role of glomalin, a protein produced by arbuscular mycorrhizal fungi, in sequestering potentially toxic elements. Environmental Pollution, v.130, n.3, p.317-323, 2004.
GRAZZIOTTI, P. H. et al. Variação sazonal da colonização de raízes de clones de híbridos de eucalipto por fungos micorrízicos no estado do Espírito Santo. Revista Brasileira de Ciência do Solo, v.22, p.613-619, 1998.

HADDAD, M. J.; SARKAR, D. Glomalin, a newly discovered component of soil organic matter: Part II - Relationship with soil properties.

Environmental Geosciences, v.10, n.3, p.99-106, 2003.

HERRMAN, S.; OELMMULLER, R.; BUSCOT, F. Manipulation of the onset of ectomycorrhyza formation by indole-3-acetic acid, activated charcoal or relative humidity in the association between oak microcuttings and Piloderma croceum influence on plant development and photosynthesis. Journal Plant Physiology, v.161, n.5, p.509-517, 2004.

JENKINS, W. R. A. A rapid centrifugalflotation technique for separating nematodes from soil. Plant Disease Report, v.48, p.692, 1964.

JONER, E.J.; JAKOBSEN, I. Growth and extra cellular phosphatase activity of arbuscular mycorrhizal hyphae as influenciad by soil organic mater. Soil Biology and Biochemistry, v.27, n.9, p. 1153-1159, 1995.

KOSKE, R.E.; GEMMA, J.N.A. modified procedure for staining roots to detect mycorrhizas.

Mycological Research. v. 48, p. 486-488, 1989.

LEAL, P. L. et al. Crescimento de mudas micropropagadas de bananeira micorrizadas em diferentes recipientes. Revista Brasileira de Fruticultura, v.27, n.1, p. 84-87, 2005.

LOPES, J. L. W. Qualidade de mudas clonais do híbrido de Eucalyptus grandis vs. Eucalyptus urophylla submetidas a diferentes regimes hídricos. 2008. $171 \mathrm{f}$. Tese Doutorado em Agronomia / Irrigação e Drenagem) - Universidade Estadual Paulista, Faculdade de Ciências Agronômicas: Botucatu, 2008. 171p.

Revista Árvore, Viçosa-MG, v.37, n.2, p.245-255, 2013 
LOVERLOCK, C. E. et al. Soil stocks of glomalin produced by arbuscular mycorrhizal fungal across a tropical rain forest landscape. Journal of Ecology, v. 92, p. 278-287, 2004.

MOREIRA, F. M. S.; SIQUEIRA, J. O. Microbiologia e bioquímica de solo. Lavras: Universidade Federal de Lavras, 2006. 729p.

NICHOLS, K. A.; WRIGHT, S. F. Carbon and nitrogen in operationally defined soil organic matter pools. Biology \& Fertility of Soils, v.43, n.2, p.215-220, 2006

NICHOLS, K. A.; WRIGHT, S. F. Comparison of glomalin and humic acid in eight native US soils. Soil Science, v.170, n.12, p.985-997, 2005.

OLIVEIRA, J. R. et al. Eficiência de fungos micorrízicos arbusculares (FMAs) em colonizar e beneficiar o crescimento de mudas micropropagadas de cará-da-costa.

Horticultura Brasileira, v. 21, n. 2, 2003.

OLIVETTI NETO, A. Qualidade de cavacos de eucalipto para obtenção de celulose kraft. Disponível em: em: <http:// www.celuloseonline.com.br/imagembank/Docs/ DocBank/dc/dc403.pdf.> . Acesso em 15 set. 2009.

PREGER, A. C. et al. Losses of glomalinrelated soil protein under prolonged arable cropping: A chronosequence study in sandy soils of the South African Highveld. Soil Biology and Biochemistry, v.39, n.2, p.445-453, 2007.

PURIN, S.; RILLING, M. C. The arbuscular mycorrhizal fungal protein glomalina: limitations, progress, and a new hypothesis for its function. Pedobiologia, v.51, n.2, p.123-130, 2007.

QUEIROZ, L. R. S.; BARRICHELO, L. E. G. O eucalipto - Um século no Brasil. São Paulo: Neoband Soluções Gráficas, 2007. 127p.

RILLING, M. C. Arbuscular mycorrhizae, glomalin, and soil aggregation. Canadian Journal of Soil Science, v.84, n.4, p.355-363, 2004.

Revista Árvore, Viçosa-MG, v.37, n.2, p.245-255, 2013
RILLING, M. C. et al. Glomalin, an arbuscularmycorrhizal fungal soil protein, responds to soil-use change. Plant and Soil, v.253, n.2, p.293-299, 2003.

RILLING, M. C. et al. Large contribution of arbuscular mycorrhizal fungi to soil carbon pools in tropical forest soils. Plant and Soil, v.233, n.2, p.167-177, 2001.

SANTOS, I. S. Fungos micorrízicos arbusculares em ambiente de mata atlântica e de Eucaliptos na região de Entre Rios, Bahia. 2001. Dissertação (Mestrado em Biologia Vegetal) - Universidade Federal da Bahia, Salvador, 2001.

SCHIAVO, J. A. E.; MARTins, M. A. Produção de mudas de acácia colonizadas com micorrizas e rizóbio em diferentes recipientes. Pesquisa Agropecuária Brasileira, v.38, n.2, p.173-178, 2003.

SCHIAVO, J. A.; MARTINS, M. A.; RODRIGUES, L. A. Avaliação nutricional de mudas de Acacia mangium, Sesbania virgata e Eucalyptus camaldulensis inoculadas com fungos micorrízicos, em casa de vegetação e em cava de extração de argila. Revista Árvore, v.31, n.4, p.701-707, 2009.

SCHÜßLER, A.; SCHWARZOTT, D.; WALKER, C. A new fungal phylum, the Glomeromycota: phylogeny and evolution. Mycological Research, v.105, n.12, p.1413-1421, 2001.

SOARES, A. C. F.; MARTINS, M. A. Influência de fungos micorrízicos arbusculares, associada à adição de compostos fenólicos, no crescimento de mudas de maracujazeiro amarelo (Passiflora edulis f. flavicarpus). Revista Brasileira de Ciência do Solo, v.24, n.4, p.731-740, 2000.

SONG, F. Q.; TIAN, X. J.; YANG, G. T. The effects of AM mycorrhizal on Populus ussuriensis. Resource Forest Science, v.17, n.1, p.86-91, 2004.

TRESEDER, K. K.; ALLEN, M. F. Mycorrhizal fungi have a potential role in soil carbon storage under elevated $\mathrm{CO}_{2}$ and nitrogen deposition. New Phytologist, v.147, n.1, p.189-200, 2000. 
TRESEDER, K. K.; TURNER, K. M. Glomalin in ecosystems. Soil Science Society of America Journal, v.71, n.4, p.1257-1266, 2007.

WRIGHT, S. F.; ANDERSON, R. L. Aggregate stability and glomalin in alternative crop rotations for the central Great Plains.

Biology and Fertility of Soils, v.31, n.3-4, p.249-253, 2000.
WRIGHT, S. F. et al. Time-course study and partial characterization of a protein on hyphae of arbuscular mycorrhizal fungi during active colonization of roots. Plant and Soil, v.181, n.2, p.193-203, 1996.

WRIGHT, S. F.; UPADHYAYA, A. A survey of soils for aggregate stability and glomalin, a glicoprotein produced by hyphae of arbuscular mycorrhizal fungi. Plant and Soil, v.198, n.1, p.97-107, 1998. 
